\title{
Research on Comprehensive Evaluation of Competitiveness of County Economic Development in Yulin City
}

\author{
Shuxi Yan \\ School of Mathematics and Statistics, Yulin University, Yulin, 719000, \\ China
}

\begin{abstract}
The downward pressure of energy economy keeps on increasing. It's the key point of social and economic work to assess the level and quality of county economic development in Yulin city to innovate the development mechanism and stimulate development dynamism of county economic. Make use of the statistical data of Yulin in 2015, select the indexes indicating development level, dynamism and potential of county economic and adopt the factor analysis method to analyze and compare the comprehensive development levels of twelve counties (districts) in Yulin city. According to the quantitative research results, put forward some suggestions to enhance the competitiveness of county economic development.

Keywords: county economy, factor analysis, cluster analysis, Yulin city
\end{abstract}

\section{Introduction}

Yulin, a national energy and chemical base, is located in the extreme northern part of Shaanxi Province and the combination belt of the central China and western China. It is with a number of provinces and cities at the junction, the city has jurisdiction over 2 districts and 10 counties. County economy is the most basic economic unit of the national economy, is an important link in the overall planning of urban and rural economic and social development. Although the level of the economy of Yulin city in the overall upward trend, but also gradually highlights the problems existing in the economic development of Yulin. Among them, the development level of county economy imbalance is most obvious, influences and restricts the sustainable development of Yulin economy society to 
a great extent. To this end, the construction measure and evaluation index of the quality of economic development in the county of Yulin City, development of the county economy identify problems and adverse factors, local counties (districts) put forward an effective way to enhance the development of county economy and feasible measures to adapt to the new normal economic development and build an upgraded version of Yulin economy has a very important practical significance.

\section{Competitiveness of county economic in Yulin based on factor analysis method}

\subsection{Indexes selection and variables description}

County economic development is affected by many factors, a few indicators cannot fully represent the development of county economy, combined with the characteristics of the county economic development of Yulin City, according to the integrity, availability and dynamic development principles, and consider the statistical data availability, selects 8 indicators of economic and social development in Yulin City were analyzed and the corresponding statistics are: gross domestic product GDP (unit: 0.1 billion Yuan, recorded as $X_{1}$ ), the growth rate of GDP (recorded as $X_{2}$ ), revenue (unit: 0.1 billion Yuan, recorded as $X_{3}$ ), the total sales of social consumer goods (unit: 0.1 billion Yuan, recorded as $X_{4}$ ), per capita net income of farmers (unit: Yuan, recorded as $X_{5}$ ), the amount of investment in fixed assets (unit: 0.1 billion, recorded as $X_{6}$ ), the total output value of animal husbandry and fishery (unit: ten thousand Yuan, recorded as $X_{7}$ ) and total industrial product (unit: 0.1 billion Yuan, recorded as $X_{8}$ ). Because of the difference between the original and the statistical data, there is a difference between the dimension and the order of magnitude. Before the analysis, the data is standardized and the standardized data are listed in table 1:

\subsection{Factor analysis and test}

Suitability tests are usually in the factor analysis before the analysis of the factors, and suitability tests including KMO test and Bartlett test, KMO test is to test the partial correlation coefficient between the variables is small, when the KMO is between 0.5-0.9, can do factor analysis; and Bartlett test is used to test whether the selected data from general multivariate normal distribution, if through a significant test showed that the data taken from $\mathrm{Yu}$ Zheng's overall distribution, can carry on the factor analysis. From the twelve counties of Yulin data for inspection, we can see that the KMO test results for 0.719 , explanatory variables can do factor analysis; significant probability Bartlett test is 0.00 . We can use the data from normal distribution to do factor analysis. 
Table 1. Standard data of evaluation indexes of county economic competitiveness in Yulin

\begin{tabular}{ccccccccc}
\hline Index & $X_{1}$ & $X_{2}$ & $X_{3}$ & $X_{4}$ & $X_{5}$ & $X_{6}$ & $X_{7}$ & $X_{8}$ \\
\hline Yuyang & 0.90 & 1.54 & 0.78 & 2.42 & 0.98 & 2.56 & 1.95 & 0.48 \\
Shenmu & 2.49 & 1.54 & 2.42 & 1.39 & 1.40 & 0.60 & 0.05 & 2.48 \\
Fugu & 0.65 & 0.29 & 0.52 & 0.47 & 1.31 & 0.09 & -0.94 & 0.95 \\
Hengshan & -0.40 & 0.63 & -0.54 & -0.09 & -0.41 & -0.23 & 0.33 & -0.46 \\
Jingbian & 0.39 & 0.58 & 1.03 & 0.12 & 1.17 & 0.55 & 1.25 & 0.54 \\
Dingbian & 0.31 & 0.01 & -0.08 & -0.32 & 0.63 & 0.72 & 1.01 & 0.32 \\
Suide & -0.68 & 0.01 & -0.67 & -0.35 & -0.89 & -0.60 & -0.32 & -0.73 \\
Mizhi & -0.70 & -0.47 & -0.68 & -0.68 & -0.61 & -0.75 & -0.94 & -0.70 \\
Jiaxian & -0.72 & -0.62 & -0.67 & -0.80 & -0.92 & -0.54 & -0.46 & -0.71 \\
Wubao & -0.80 & -0.47 & -0.70 & -0.87 & -0.89 & -0.87 & -1.49 & -0.74 \\
Qingjian & -0.73 & -1.48 & -0.70 & -0.64 & -0.89 & -0.71 & -0.09 & -0.71 \\
Zizhou & -0.68 & -1.53 & -0.68 & -0.65 & -0.87 & -0.79 & -0.34 & -0.69 \\
\hline
\end{tabular}

\subsection{Factor extraction}

By using the method of principal component analysis of the selected indicators were screened by SPSS19.0 analysis shows that the characteristics of the first factor value is 6.221 , the original variable contains $77.76 \%$ of the total variance, the cumulative variance contribution rate was $77.76 \%$, the characteristics of second factor value is 1.078 , the original variable contains $13.471 \%$ of the total variance, cumulative variance contribution the rate is $91.231 \%$, the loss of the original variable information less, factor analysis is better; the rotation factor, the total cumulative variance contribution rate of each factor does not change, but change the original variables explain the proportion of variance, the variance contribution of each factor was changed, which has more practical explanatory factor; factor analysis the stone figure shows that the first factor and second 
factor eigenvalues greater than 1 , the rest of the characteristic value of the factor is less than 1, and the first factor and second for The sub line between the relatively steep, all factors of the connection between relatively flat, contribution of the first two factors of original variables is relatively large, the remaining factor contribution is relatively small, so select the top two factor analysis.

\subsection{Factor rotation}

By SPSS19.0 analysis, the factor loading matrix after the discovery, explain the two factors on the original variable meaning is fuzzy, so using the maximum variance method of factor loading matrix of orthogonal rotation, in order to make practical explanatory factor. The factor loading matrix after rotation is shown in Table 2. In addition, the rotated factor loading diagram also shows that the factor 1 and factor 2 contain more information of the original variables.

Table 2. Matrix of load of factors after rotation

\begin{tabular}{|c|c|c|c|c|c|c|c|c|c|}
\hline \multicolumn{2}{|c|}{ Index } & $X_{1}$ & $X_{2}$ & $X_{3}$ & $X_{4}$ & $X_{5}$ & $X_{6}$ & $X_{7}$ & $X_{8}$ \\
\hline \multirow{2}{*}{ Component } & 1 & 0.939 & 0.698 & 0.934 & 0.642 & 0.835 & 0.449 & 0.128 & 0.972 \\
\cline { 2 - 9 } & 2 & 0.305 & 0.552 & 0.287 & 0.675 & 0.425 & 0.870 & 0.936 & 0.189 \\
\hline
\end{tabular}

\subsection{Calculate comprehensive factor score}

The factor score coefficient was estimated by regression method with SPSS19.0: $F_{1}=0.28 X_{1}+0.09 X_{2}+0.284 X_{3}+0.023 X_{4}+0.193 X_{5}-0.128 X_{6}-0.285 X_{7}+0.335 X_{8}$ $F_{2}=-0.134 X_{1}+0.12 X_{2}-0.144 X_{3}+0.223 X_{4}-0.016 X_{5}+0.423 X_{6}+0.584 X_{7}-0.224 X_{8}$

The scores of the two factors are shown in Table 3.

Table 3. Scores of two factors

\begin{tabular}{|l|l|l|l|l|l|l|l|l|l|l|l|l|}
\hline$F_{1}$ & 0.14 & 2.57 & 1.19 & -0.51 & 0.44 & -0.09 & -0.64 & -0.44 & -0.69 & -0.38 & -0.85 & -0.74 \\
\hline$F_{2}$ & 2.59 & -0.48 & -0.77 & 0.39 & 0.72 & 0.72 & -0.15 & -0.72 & -0.39 & -1.10 & -0.31 & -0.51 \\
\hline
\end{tabular}

Finally, we took the proportion of the variance contribution rate of each factor in the total variance contribution rate as the weight. The comprehensive score of the county economic competitiveness is obtained. The formulation is:

$$
F=\frac{56.433}{91.231} F_{1}+\frac{34.798}{91.231} F_{2}
$$

Table 4. Factors scores and ranking of county economic comprehensive power

\begin{tabular}{|c|c|c|c|c|c|}
\hline Yuyang & Shenmu & Fugu & Hengshan & Jingbian & Dingbian \\
\hline 1.06 & 1.41 & 0.45 & -0.16 & 0.54 & 0.21 \\
\hline 2 & 1 & 4 & 6 & 3 & 5 \\
\hline Suide & Mizhi & Jiaxian & Wubao & Qingjian & Zizhou \\
\hline-0.45 & -0.54 & -0.57 & -0.65 & -0.64 & -0.65 \\
\hline 7 & 8 & 9 & 11 & 10 & 12 \\
\hline
\end{tabular}

Table 4 shows the ranking of the economic competitiveness of the county of Yulin city as follows: Shenmu, Yuyang District, Jingbian County, Fugu County, Hengshan District, Suide County, Mizhi County, Qingjian County, Jia County, Wubao County and Zizhou County. The top 6 counties, located in the Yulin city are located in the north, the ranking of the 6 counties, geographically located in Yulin City, south. Obviously, the development of county economy in Yulin is 
very uneven, and there is an obvious imbalance between the development of the north and the south.

\section{Result analysis and countermeasure proposals}

\subsection{Result analysis}

Using the actual statistical data of Yulin city in 2015 the county economic indicators, using factor analysis method to conduct a comprehensive quantitative analysis and calculation, the economic competitiveness of the county of Yulin city rankings, ranked first in Shenmu county and ranked third in Fugu County, is a national "Shenfu coal field" hinterland, with extremely rich and high-quality coal resources after, the construction and development of national energy and chemical industry base in Yulin City, through the coal resources gold for ten years, the county economy has been rapid development, has entered the ranks of the national hundred counties, typical for coal rich; comprehensive economic competitiveness ranked second in Yuyang District, Yulin City is located, political, cultural and educational center of Yulin the city also has abundant coal, salt and other mineral resources, the same with the national energy and chemical industry base construction and development of the tide, After entering Shaanxi province municipal area before the ten strong, superior performance, prospects for; fifth, ranking third in Jingbian county and Dingbian County, with abundant oil and gas resources, coupled with flat geographical conditions, in recent years, the sustainable development of modern agriculture, has been the extraordinary. And ranked by the southern six counties, mostly because geography is relatively remote, traffic is not convenient, lack of resources, no resources, no regional advantages, compared with the Yulin city six county economic development form distinctive. As a new type of Resource-based City, Yulin City, the economic resources must have the aid of first mover advantage, accelerate the adjustment of industrial structure and efforts to develop alternative industries, local characteristic innovation development mechanism and boost the economic vitality of the county, the transformation, promote development and coordinated development of county economy balance.

\subsection{Countermeasure proposals}

Adhere to the traditional advantages of resources do not shake. China's economic change of energy and resources will not demand, north of the city of Yulin in six counties, especially coal, oil and natural gas resource rich Shenmu, Fugu County, Jingbian county and Dingbian County, superior resources and industrial competitiveness of the one and only remains strong and optimistic, but will continue to be bigger and stronger. To promote coal gasification, coal liquefaction, coal coking and coal industry, and the coordinated development of supporting the development of new materials industry, equipment manufacturing and logistics and other related industries, let Yulin become the new resources and resources, worthy of the name. 
Adjust measures to local conditions and develop special industries to promote the coordinated development of county economy. The lack of resources and geographical advantages, the development of county economy is lagging behind the six counties in the south, the government should strengthen the fiscal policy support, scientific and overall planning, renovation and expansion of roads, to promote the development of characteristic planting, breeding characteristics, characteristics, characteristics, characteristics of textile processing culture and tourism industry, and strive to build the development pattern the county industrial diversification, promote the development of dislocation in six southern counties and the new characteristics of development. For example, the characteristics of agriculture, to develop dry farming, agriculture, water-saving agriculture, ecological agriculture, and strive to build the Yulin potato, small grains, red dates, mutton, vegetables and desert mountain Apple six county public brand; cultural characteristics, can focus on building the Great Wall village, along the Yellow River tourism, tourist routes to Chairman Mao fine county in Shaanxi Province and suburban ecological leisure, Rural Folklore etc..

\section{Acknowledgement}

The research is the result of Planning Project of Social Science Special Foundation in Yulin City (Grant No.YLSKGH2016-18) and Cooperation Project of Industry, Academy and Research of Science and Technology Bureau in Yulin City (Grant No. 2016-2018).

\section{References}

[1] Shen Qunyi, Chen Xiangman, Huo Xuqiang, Empirical Analysis and Evaluation on the Key Competence of County Economy in Hunan Province, Journal of Xiangtan University (Philosophy and Social Sciences), 35(1), pp. 48$52,2011$.

[2] Liu Chuanming, Shang Zhengyong, Hu Xiangfeng, Evaluation of urban economic competitiveness based on scientific development: a case of main cities in Huaihe River Basin, Journal of Jiangsu Normal University (Natural Science Edition), 33(3), pp. 19-23, 2015.

[3] Xue Jiliang, Du Fenglian, The Assessment of Non-public Economic Development Environment and Competitiveness in Inner Mongolia, Journal of Radio \& TV University (Philosophy \& Social Sciences), (3), pp. 3-8, 2014.

[4] Wu Shouping, Qi Hongyan, Industrial Structure and Competitiveness Effect of the County Economic Development - A Case Study of Less Developed Areas in Guangxi, Reformation \& Strategy, 27(11), pp. 97-99+118, 2011. 